\title{
Recent advances and future developments in forensic toxicology
}

\author{
Helena M. Teixeira
}

Published online: 25 March 2014

(C) Springer-Verlag Berlin Heidelberg 2014

Toxicology is the study of poisons and poisoning, and has an ancient and venerable history. The science of toxicology has come a long way in the past centuries with significant advances in analytical technologies as well as in the various disciplines of toxicology. There is no greater analytical challenge in forensic toxicology than the "general unknown," the search for drugs or poisons that might have caused a death, impaired a driver, or drugged the victim of sexual assault. Toxicology has developed into a science that brings together many disciplines, analytical chemistry, biochemistry, and genetics, which may have once appeared to be very different. In fact, forensic toxicology has benefited from advances in broader areas of science and technology, but although technology has advanced in the past 170 years, the forensic toxicologist still experiences the same analytical challenges.

The demand for toxicological examinations will continue to grow, outpacing the ability of each country's

Published in the topical collection Forensic Toxicology with guest editor Helena Teixeira.

H. M. Teixeira $(\bowtie)$

National Institute of Legal Medicine and Forensic Sciences, Centre

Branch, Largo da Sé Nova, 3000-213 Coimbra, Portugal

e-mail: helenateixeira@dcinml.mj.pt

H. M. Teixeira

Faculty of Medicine, University of Coimbra, 3000-548 Coimbra, Portugal forensic toxicology laboratories to process them. This solicitation aims to increase the amount of research, development, refinement, and/or improvement of analytical techniques used by forensic laboratories to gather data on complex chemical substances and their metabolites. It also seeks research into tools and technologies that will promote faster, widely applicable, rugged, less costly, and less labor-intensive equipments for identification, collection, preservation, and/or analysis of biological samples for controlled substances and other toxins, to develop new analytical techniques, and nondestructive techniques. As far as technology advancement is concerned, companies will compete against each other to produce an instrument or solution that will reduce analysis times, increase sensitivity of the instrument, and reduce sample preparation. With so many chemicals and drugs in existence, new psychotropic substances and the various matrices, there will most likely be a demand for toxicologists. With this in mind, they will need efficient yet thorough methods.

Undoubtedly, the future may provide greater and greater toxicological information, but it is not a certainty that this will add interpretive clarity for the forensic toxicologist.

In the future, the forensic toxicologist will remain the person who examines blood, body fluids, and tissue samples of the victim to see if the cause of death was a drug or poison; when a forensic pathologist cannot find an obvious cause of death after an autopsy, the forensic toxicologist will carry on determining specifically all of the drugs and poisons present along with the quantities at the time of death, and shaping if any 
metabolites are present, as well as any drug interactions, and examining any history of drug use by the victim. To remain qualified as a forensic toxicologist, she/he will always have and improve her/his background in analytical chemistry or toxicology. The analytical techniques, biological matrices, postmortem studies, therapeutic drug management or monitoring, driving impairment, workplace drug testing, pharmacodynamics monitoring, and toxicogenetics/toxicogenomics studies will continue being some of the targets of forensic toxicology.

I thank all authors for submitting their remarkable contributions for this special issue; the referees for their careful, critical, and always constructive appreciation; and the Editorial Office and the Editors for their friendly and welcoming support.

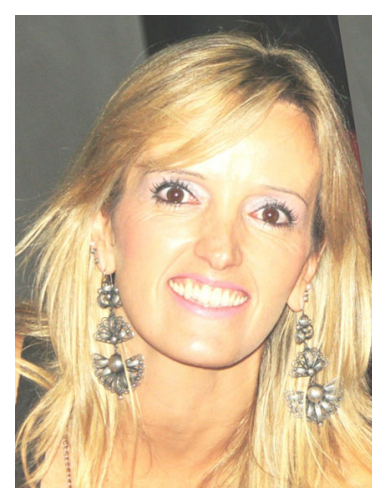

Helena M. Teixeira is a Legal Medicine Superior Specialist at the Forensic Chemistry and Toxicology Service of the National Institute of Legal Medicine and Forensic Sciences of Portugal, and she is Professor at the Medicine Faculty of the University of Coimbra. She has a Pharmaceutical Sciences Degree, a Superior Degree on Legal Medicine, a Master's degree on Experimental Pathology, and the Ph.D. on Biomedical Sciences. She has published over 60 papers, and her main topics are drugs and driving, postmortem toxicology, and analytical toxicology. She was the President of the 51st International Meeting of the Association of the Forensic Toxicologists, held in Madeira, in September 2013, and she has been the TIAFT Regional Representative of Portugal since 2004, member of the Young Scientist Board since 2007, and Member of the Advisors Board of the Brazilian Society of Forensic Sciences since 2013. 